Marquette University

e-Publications@Marquette

5-1-2017

\title{
There is Nothing It is Like to See Red: Holism and Subjective Experience
}

Anthony F. Peressini

Marquette University, anthony.peressini@marquette.edu

Accepted version. Synthese, (2017) online prior to print. DOI. (C) 2017 Springer International Publishing AG. Part of Springer Nature. Used with permission. 


\title{
There is Nothing It is Like to See Red: Holism and Subjective Experience
}

\author{
Anthony F. Peressini
}

Received: July 24, 2016 / Accepted: May 1, 2017

Version 1.6aw

\begin{abstract}
The Nagel inspired "something-it-is-like" (SIL) conception of conscious experience remains a dominant approach in philosophy. In this paper I criticize a prevalent philosophical construal of SIL consciousness, one that understands SIL as a property of mental states rather than entities as a whole. I argue against thinking of SIL as a property of states, showing how such a view is in fact prevalent, under-warranted, and philosophically pernicious in that it often leads to an implausible reduction of conscious experience to qualia. I then develop a holistic conception of SIL for entities (not states) and argue that it has at least equal pre-empirical warrant, is more conservative philosophically in that it decides less from the a priori "armchair" and enjoys a fruitful two-way relationship with empirical work.
\end{abstract}

Keywords subjective experience - phenomenal consciousness $\cdot$ creature consciousness $\cdot$ qualia $\cdot$ holism . reductionism $\cdot$ consciousness $\cdot$ hard problem $\cdot$ subjectivity $\cdot$ qualitative character

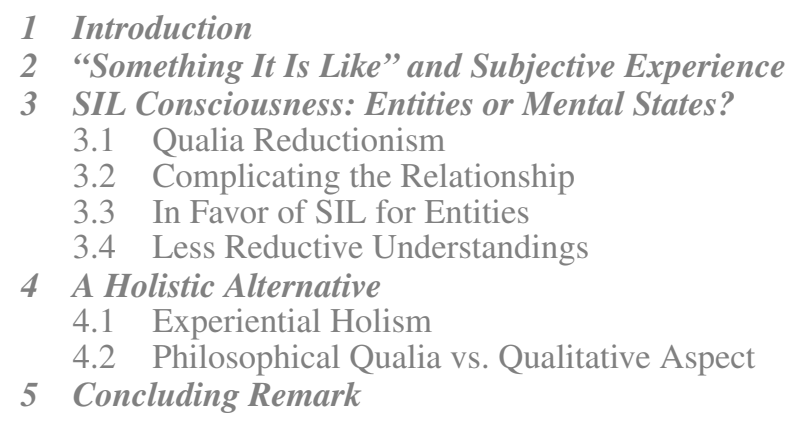

Anthony F. Peressini

Department of Philosophy

Marquette University, Milwaukee, WI

E-mail: anthony.peressini@mu.edu

web: academic.mu.edu/peressini/ 


\section{Introduction}

Not withstanding a compelling cataloging of as many as forty different senses of "consciousness" (Vimal 2009), arguably the most prominent and problematic is Thomas Nagel's (1974) version of the "something-itis-like" articulation. It can be found widely in philosophy, psychology, neuroscience, and cognitive science. It has come to be the intuitive, pre-theoretic, or even formal basis of many of the most influential approaches to the central issue of consciousness: the problem of conscious experience. ${ }^{1}$ Influential philosophical examples include Ned Block $(1995,2002)$ and his notion of phenomenal consciousness, David Chalmers $(1995,1996)$ and the hard problem of consciousness; scientific examples include Guilio Tononi (2008), and Christof Koch (2004, 2012).

Despite widespread application of the notion of "something-it-is-like" (SIL), an important and generally overlooked confusion remains in its general use. The concept SIL is applied without much in the way of scruples to both entities ("what it is like to be a bat") and to such entities' experiential states ("what it is like to see red"). ${ }^{2}$ These are not identical uses, nor are they obviously equivalent. Most thinkers ignore altogether the distinction or pass over it quickly, tapping into the intuitive warrant of SIL for entities (like us) and then with a wave of the hand moving on to theorize about mental states with "something it is like" to be in them, apparently assuming that one can think of entity SIL in terms of state SIL, without remainder. Ignoring the relationship between SIL for entities and for states gives rise to further confusion with conscious experience's relationship to the notorious notion of "qualia." In particular, it seems to entice many thinkers into assuming that SIL consciousness for entities is nothing more than having states with qualitative or phenomenal properties.

Returning to the original source of the SIL concept at the entity level affords new and richer possibilities for how we can understand and continue scientifically to investigate subjective conscious experience. In particular, the holistic nature of first person experience coupled with empirical work that involves holistic notions like fields, dynamical systems theory, and integrated information suggest that a more holistic philosophical conception may be in order as well. Such a entity-level holistic conception of SIL helps narrow in on the problem of conscious experience without lapsing into one of the two polar camps of either "papering over" the current explanatory gap or "hardening" it (a priori) into an (empirically) intractable problem.

In what follows I present and develop precisely how the conscious experience of entities in the SIL sense is often reduced to mental states with qualitative properties, including showing what motivates the reductive impulse, where it is present in current prominent accounts of experience, and why I think it is mistaken. I then offer a holistic alternative conception of SIL for entities, making the case for its warrant conceptually, pre-theoretically, and empirically. The plan of the paper is as follows. Section 2 is an argument for a particular understanding of the contours of the problem of conscious experience and its relationship to SIL. I show in Section 3 how conflating SIL for entities and states has clouded the current debate and I argue for the primacy of the entity-level SIL. Section 4 is a development of a holistic conception of conscious experience for entities, including a case for its advantages over standard reductive conceptions.

\footnotetext{
${ }^{1}$ Key components of Nagel's seminal paper and its concerns and its framing of the problem are present very clearly in a largely unacknowledged paper almost 25 years older by Brian Anthony Farrell (1950), entitled "Experience." Farrell even asks what it would be like to be or to hear like a bat (p. 183). And roughly three years prior to Nagel, Timothy Sprigge (Sprigge and Montefiore 1971, Sec. VIII) writes that if an entity is conscious, "then being that organism will have a certain definite complex quality at every waking moment..." (p. 168, italics in the original).

2 In order to distinguish conscious states from conscious entities, one variously finds alternate terms for "entity," for example, "creature" (as in creature consciousness) or "subject" (as in the experiential subject). I will use "entity" and "entity consciousness."
} 


\section{2 "Something It Is Like" and Subjective Experience}

The target of inquiry here is the notion of a conscious experiencer. This notion is grounded in the intuitive, pre-theoretic concept of there being "something it is like" to be such a conscious entity. ${ }^{3}$ I understand this conception to be providing roughly the same pre-theoretic grounding as, for example, Block's phenomenal consciousness (p-consciousness), Chalmers' "hard problem" characterization, or less directly Uriah Kriegel's (2009, Ch. 1, Sec. 2) rigidified definition of phenomenal consciousness in terms of "the mystery of consciousness." While both Block and Chalmers explicitly tie their respective conceptions to SIL, Kriegel elects initialy to avoid SIL because "it is probably unlikely to be of much help to the unintitaited" and because "most importantly, it is of no help in extracting the substantive core of partially confused disputes, since typically disputants disagree on what kinds of state have something it is like to be in" (Kriegel 2009, p. 4). Kriegel's extended effort to delineate a pre-theoretic conception of the problem of consciousness is helpful and all too rare, but his reasoning against utilizing SIL is not entirely convincing. ${ }^{4}$ Nonetheless, the SIL locution (at the state or entity level) is helpful in doing just what Kriegel (wisely) is attempting: to locate the "epicenter" of the mystery of conscious experience by the use of a predicate that picks it out from an "everyday use" (pre-theoretical) perspective. And this mystery is neatly pointed to by the locution that for some physical entities there is "something it is like" to be them. ${ }^{5}$

To make more precise the SIL locution, let the notation $\operatorname{SIL}(x)$ be understood as the predicate "there is something it is like to be $x$," where $x$ is an entity, not a property or mental state. Thus SIL(Obama) is true, SIL(my thermostat) is presumably false, and SIL(my toothache) is undefined, since mental states or properties like toothaches are not within the domain of the SIL predicate. I am suppressing the time indexical, but of course $\operatorname{SIL}(x)$ will vary with time, so that the precise composition of the subjectivity that makes SIL(Obama) true at a given time will generally be different at a different time. ${ }^{6}$ Notice that this predicate formally leaves open whether there is in fact any natural property in the world to which the predicate corresponds. I am taking entity-level SIL to be the primitive notion, and so if needed, one could then define SIL for states, $\operatorname{SIL}_{\mathrm{s}}(x, y)$, as "there is something it is like to be $x$ and an aspect of $x$ 's experience includes state $y$," where $x$ is and entity and $y$ is a mental state. I will make an extended case for beginning with SIL for entities rather than states below in Section 3.3. In general, I will avoid the term "p-conscious," since it is variously applied to both mental states and entities and thus cuts across a line to which I wish to pay close attention.

\footnotetext{
${ }^{3}$ As Nagel made clear, "something it is like" must be understood in the sense of something it is like to be the entity for the entity itself, thus ruling out cases like "there is something it is like for Nixon to be dead," which of course there is, but there is nothing it like for Nixon to be dead for Nixon himself, thus it is (presently) false that there is something it is like to be Nixon in the SIL sense.

${ }^{4}$ It seems that it is in fact the uninitiated who find SIL most illuminating in pinning down what philosophers are getting at with the problem of subjective experience: when introducing this material philosophers almost always use the "what is is like" locution to pick out the qualitative aspect of a pain or seeing red, as Kriegel himself does (2009, Ch. 1, Sec. 1 and Ch. 2, Sec. 3). What is more, there is preliminary experimental reason to think that non-philosophers employ something like a SIL concept in attributing experience (Peressini 2014). Kriegel's second and primary consideration, that SIL is of no help because disputants disagree as to which states have SIL, is not telling in this context either, since I will be focusing on its application to entities not states. And I could not agree more: an attempt to characterize definitively which states have SIL is an exercise in "armchair philosophy" futility, and this is precisely what I seek to avoid here.

5 Of course in the end Kriegel's rigidified definite description and Nagel's SIL are quite likely to be co-extensive. However, for the purpose here of pre-theoretically picking out the phenomenon under investigation, SIL is more helpful, if not inevitable, and also without cost in this context, since the question of precisely which states have SIL is not at issue. A kind of compromise might be to understand the problem of subjective experience using the rigidified definite description "whatever it is that allows some physical systems to have SIL."

6 The question of what the "minimal entity" is with SIL naturally arises-presumably losing one's arm would not eliminate SIL for the person. But would parts of a person's brain themselves have SIL, distinct from the person's SIL? Quite possibility, but this would seem to be an empirical question; see Tononi (2008).
} 
In the context of this paper, qualia are understood in the standard way as the "qualitative properties" of (conscious) experience, i.e., the special properties of certain mental states that are distinctive to experiencers, are practically private and ineffable, are (at least relatively) intrinsic, and hence have to be characterized ostensively with the SIL notion as to how the given state actually "feels" (in a generic experiential sense) to the experiencer. For example, if one is seeing a stop sign then the way the red appears in his/her phenomenal field is a red quale. There are (presumably) qualia associated with all sense modalities and other states like emotions, moods, etc. I move back and forth between the terms "qualia" and "phenomenality," depending on context, with the understanding that qualia are the phenomenal properties of mental states. Phenomenological properties are to be understood as those that a subject's experience has as experienced; they include standard though not uncontested things like the experiential properties of perceptual, affective, emotional, and conative states among others perhaps, including higher cognitive states.

Discussions of conscious experience inevitably involves the notion of "explanatory gap," so let me orient the SIL predicate to that way of understanding "the mystery" of subjective consciousness. One cannot but be impressed by the difference between first person descriptions of experience and third person accounts of experiencers. As Nagel so influentially pointed out, such third person approaches naturally pass over altogether the SIL of the subject, and there is an explanatory and/or inferential gap between these perspectives. This gap has since been theorized in various ways-most notably by Joseph Levine (1983) as a gap between phenomenal properties and neuro-physical properties, but also between phenomenality and functional roles (Chalmers 1995). ${ }^{7}$

For purposes here, I propose to understand "the gap" as an apparent explanatory gap between configurations of physical entities with SIL and those without. ${ }^{8}$ Again, in keeping with pre-empirical agnosticism regarding the status of the ultimate referent of the SIL predicate itself, I am not here assuming there actually is a "hard" problem style gap, i.e., one that is metaphysically fundamental or epistemologically immutable, hence the qualifier "apparent." Rather, my starting point is that there is indeed at least an epistemological gap at the present time between our best frameworks and account(s) of the mind/brain system and first person subjective experience (SIL): our current scientific/philosophical explanatory framework is incapable of smoothly subsuming first person subjective experience or convincingly revealing why it is categorically precluded from subsuming it (Block 2009). ${ }^{9}$ A helpful way of articulating this explanatory gap is that our current understandings fail to address the following primary gap-revealing question:

(PG) Why is it that the particular causal, functional, informational, neural system under consideration has experience at all.

This question must be distinguished from another important and related secondary gap-revealing question:

(SG) Why and how it is that the particular experiencer under consideration has the particular experience it does at a given moment, including especially its qualitative aspects.

It is secondary in that its coherence depends on the coherence of the PG, and not vice versa. There are of course different sub-versions of a SG question, e.g., (a) how it is that some mental states (or more generally mental features) are aspects of SIL experience at a given moment and others are not? Or (b) why and how does a particular kind of qualitative aspect come to be in an entity's SIL? And variations of (b) might also

\footnotetext{
7 As an historical note, an argument for this explanatory gap appears much earlier in the neurophysiologist Emil Du Bois-Reymond's 1872 public lecture in Leipzig entitled "Über die Grenzen des Naturerkennens" ("On the Limits of Our Knowledge of Nature"). See Finkelstein (2013, Ch. 12, esp. pp. 213-14) for details. Thanks to a reviewer for pointing this out.

8 This should be taken to be equivalent to explaining why for an entity there is experience at all, not necessarily why the entity's experience is $X$ as opposed to $Y$.

9 There is also a natural way of reading Nagel (1974) as ultimately endorsing roughly this kind of gap.
} 
be run for kinds of aspects of SIL other than qualitative ones. But again, it is PG that is the central question of conscious experience, as its explanandum (SIL) is a pre-supposition for the others. ${ }^{10}$

It is important to note the difference between PG, which articulates the mystery of consciousness in terms that leave open the possibility of empirical resolution, and Chalmers' (1995) "hard problem" articulation. While in places Chalmers articulates the problem along the lines of PG, ultimately he argues that the hard problem cannot be solved on "on the cheap" by physical explanation (p. 18), that in fact, because of the very nature of the explanandum, experience, it is what is left over after all the structure and dynamics of the systems have been accounted for. Some of the examples of experience he gives are "the examples of the felt quality of redness, the experience of dark and light, the quality of depth in a visual field" (p. 10). He understands the SIL of these states as something that can be seen a priori as not being explainable in terms of the physical, functional capacities and dynamics of the system. This is initially compelling because it taps into the reader's understanding of SIL in terms of qualia: intrinsic, non-relational features of mentality that are by definition (i.e., "a conceptual fact", p. 12) left over after physical explanation is exhausted. This goes beyond PG and embodies a "hardening" of the mystery of consciousness to the point of being able to know a priori that no empirical physicalist resolution could be forthcoming. As I will develop at length below, conceptually linking SIL to qualia in this way is unwarranted and so to the extent that this link is not inevitable, neither is the metaphysical "hardening" of the problem of experience.

As mentioned briefly above, the SIL consciousness of an entity at a given time (or interval of time) seems to have distinct and overlapping identifiable features or aspects, including of course what are standardly referred to as "mental states," among other things. I turn now to the question of the structure of SIL consciousness in order to establish a few general characteristics.

Consider a "momentary slice" of SIL consciousness, for example, some of the aspects of my SIL at this moment include things like seeing the green wall in front of me with lots of other things like people and tables in the periphery; feeling the chair underneath me; the pressure the small piece of apple is exerting on the two of my teeth between which it is lodged, an awareness of my body swaying slightly to the beat of the non-vocal music I have playing in my headphones to block the potentially distracting sounds of my environment-some of which make it through like the intermittent give and take hum of the conversation of my table-mates that I can't quite make out and the buzzing of the coffee grinder; having a "clouded" and tight general sensation in the band of my head from my ears across my forehead and eyes; remembering my breakfast; asking myself in a vague semi-linguistic way whether I am hungry; thinking explicitly about how long it has been since my last allergy pill; feeling an irritating bodily anticipation of a pesky fly in the area landing again on my arm; a persistent unfocussed low-grade anxiety growing out of a vague recognition of the small amount of time remaining in my writing session, which is felt as a sensation in my chest linked to a slight sense of hurry pervading my experience generally; besides this anxiousness other general tenors of my experience are an excited anticipation of a new book scheduled to be in my mail today, and a sense of comfort about my surroundings because it is my regular work space and table.

\footnotetext{
10 One might object, saying that in terms of investigation, working on questions like SG's is legitimate and actually happens even before PG has been answered and therefore shows that they are as primary as PG. But this is a best a methodological primacy, not a conceptual one. One might similarly point out that one has more clarity and certainty about whether an entity has experience at all than about of what the entity's particular experience consists. But again this observation, while plausible, is not germane to the conceptual priority that is the target here. Tom McClelland (2017) very helpfully carves the explanatory terrain up in much the same way, defending at length the separability of the "consciousness question" and the "character question" and the possibility of one being "hard" and the other "easy." My point of departure from McClelland concerns his apparent willingness to go along with what I call "qualia reductionism" (Sec. 3.1 below), namely that the consciousness (SIL) of the entity can be thought of as nothing more than its having states with (qualitative) character; see McClelland (2017, esp. Sec. 3.1, paragraph 2).
} 
Hopefully such a description is quite natural to anyone who cares to reflect on his/her SIL at a moment. ${ }^{11}$ Many elements of this description are qualitative in the standard sense (perceptions, feelings, etc.), but others seem to be cognitive—some verbal and some not—and these may or may not have a qualitative component. ${ }^{12}$ A crucial point to notice is that SIL consciousness has a lot more to it than the familiar mental states of folk psychology coupled with their (second order) qualitative or phenomenal properties (qualia): there are structural and relational aspects as well. While my SIL at the moment can be described as consisting of the "states" and "qualities" listed above, this collection presents as a whole; they are united as aspects of my SIL at the moment (Searle 2000; Bayne and Chalmers 2003; Bayne 2007, 2010). ${ }^{13}$ In a like way, they are all related to one another by being contemporaneous. Also, some of the elements present as "remembered" and hence parts of them were related to others as being prior in time, similarly for some being "anticipations" and anterior in time. What is more, as phenomenologists have pointed out, in general to have a sense of present, one must have a sense of the immediate past (retention) and "almost here" future (protention). Also, my SIL includes a spatial organization of (only) some of the aspects. And the "moment" that my SIL consists of is not really a point moment in the mathematical sense; it has "temporal width," though small enough that my sense of simultaneity is not violated. ${ }^{14}$ Other non-qualitative structural features of SIL may include its falling into different modes (cognitive, perceptual, linguistic, conative, affective, etc.) and sub-modes within these; general affective tones, and relationships among and within some of its kinds of aspects (i.e., similarity, difference, identity, logical, rational, causal, etc. $)^{15}$

That SIL consciousness has, in addition to its qualitative aspects, a plethora of interrelated structural and other (immediately) relational features that jointly constitute it might remind one of Levine's (2001) and Kriegel's (2009) distinction between the qualitative and subjective character of a mental state. In particular, Kriegel points out that conscious experience has the following two features: a qualitative character and a "for-me" or subjective character. Accordingly, when I experience a clear blue sky the experience has a qualitative-character (q-character) of "bluishness" and a subjective-character (s-character) of "being mine" in that intimate first person subjective sense (Kriegel 2009, Ch. 1, sec. 3). This insight is important and seems on the right track, especially Kriegel's care in separating the peripheral question of the qualitative

\footnotetext{
11 As Jered Janes rightly points out, one might well question whether the above is a realistic description of what one actually experiences in a moment - that perhaps it is too rich and complex to be consciously experienced in a moment. Indeed it seems an open question (ultimately decidable only with empirical detail) as to what constitutes a conscious "moment" in terms of its the temporal expanse and depth of SIL detail. While it is clear that "individual" aspects of SIL are never experienced in isolation (e.g., having a red quale), still one may "experience" an aspect as more or less isolated or clear or focussed depending on whether one is attending to or reflecting on the particular aspect. This rough idea is captured in the phenomenological tradition's distinction between pre-reflective/natural/normal experience and reflective/theoretical/philosophical experience. The precise expanse of a conscious "moment" seems to depend on the level and kind of focus of attention at play and also upon global and background features of consciousness (e.g., level of agitation or being fully awake). Such considerations raise many important questions—ones I will not take a stand on here-including whether reflecting on (or judgments about) an aspect of experience intrinsically involves the original phenomenality associated with that aspect of experience, merely a derivative (representational) version of the original phenomenality, or no version of it at all (Bayne and Montague 2011). Perhaps some of the detail that we can extract from a moment of consciousness is only present in the moment latently, or upon reflection. So in this sense, depending on how we construe "a moment" and the liminal boundary conditions, it may well be that we are not always aware at that moment of all of the aspects of our SIL at that moment. I certainly would not want to rule on that pre-empirically. For purposes here, I need only an example of a "moment" of SIL that has enough to it to illustrate its complex relational and structural aspects in addition to its qualitative.

12 While this of course (as per Kriegel's point above) is contentious, nothing in what I will say depends on whether or not there are (cognitive) states that lack qualitative aspects.

13 The occurrent mental "states" that are part of my SIL at the moment can no doubt be overlaid with all sorts of dispositional states like beliefs, desires, fears, etc., some of which may be themselves part of my SIL, either immediately or via an occurrent thought with them as its object.

14 See Zahavi (2010, 320-21) for a discussion of Husserl's (1968; 1969) insight on the duration of experience.

15 In addition to these structural and relational features of SIL, there may be further non-qualitative aspects, e.g., semantic or intentional. It is sufficient for purposes here, however, to focus on the less contentious ones listed above.
} 
aspect from what he notes as the "central" notion of a theory of consciousness, the subjective (Kriegel 2009, Ch. 2, sec. 3, final paragraph). ${ }^{16}$

Nonetheless, since Kriegel develops it within a framework that embodies the standard (generally) unquestioned assumption that such investigations should begin with or prioritize mental states with special phenomenal properties and not entities, it falls prey to the problems I will develop in the next section. In particular, it gives short shrift or passes over altogether the non-qualitative structural features of conscious experience, that is, those features of SIL that present immediately as having a relational character (degree attended to, bodily location, spatial location, temporal location, etc.) or modal (imagistic, recalled, tactile, visual, etc.) or composite (self talk, seeing the wall, hearing a fly, etc.) or global (feeling: anxious, bored, on edge, drunk, nauseous, angst, euphoric, energetic, restless, etc.). ${ }^{17}$

\section{SIL Consciousness: Entities or Mental States?}

Current philosophical discourse on phenomenal consciousness reveals almost universal use of the SIL notion to ground the discussion, but thinkers often move quickly between SIL applied to entities ("what it is like to be a bat") and applied to such entities' experiential states ("what it is like to see red"). If it is addressed at all, the distinction is quickly passed over, tapping into the pre-theoretical understanding of SIL for entities (like us) and then with a wave of the hand moving on to theorize about mental states with "something it is like" to be in them. The underlying assumption seems to be that one can think of entity SIL in terms of state SIL, without loss, a kind of "qualia reductionism."

In this section I make an extended case for grounding our understanding of SIL at the level of entities, rather than mental states. I trace how the intuitive warrant for the SIL approach, which began with Farrell and was given its current form by Nagel as an entity-level notion, has diverged from this understanding to focus on "mental states with SIL." I argue that entity-level SIL should indeed be taken as the more fundamental notion - that it cannot plausibly be taken as identical to or reducible to a simple "sum" of qualitative statesand that a consequence of such undue focus on SIL as qualia is a tendency to either overly mystify the problem of experience or to miss it altogether by "defining" it away.

\subsection{Qualia Reductionism}

One might think that the conflation of entities and states traces back to Nagel's original formulation, and it may well, but a look at Nagel's actual statement of the SIL notion suggest that the primary use of SIL is as a property of experiencers, not of their states of experience. Consider Nagel's $(1974,436)$ own articulation, "... the fact that an organism has conscious experience at all means, basically, that there is something it is like to be that organism. There maybe further implications about the form of the experience ... but fundamentally an organism has conscious mental states if and only if there is something that it is like to be that organismsomething it is like for the organism. We may call this the subjective character of experience."

\footnotetext{
16 Of course, Wittgenstein $(1953, \S 53)$ and representationalists who endorse the transparency of perceptual experience would deny this.

17 An advocate of Kriegel's approach might suggest that the structural and relational aspects of SIL are built into the s-character of a state. Again, this will come up below, but the structural features of experience as I develop them go well beyond the "for-me" character. I will argue further that such state-based properties cannot adequately capture the complex and holistic (deeply relational) nature of SIL in a way similar to how a study of the properties of a neuron cannot capture the meso- and macro-level properties of ensembles of neurons.
} 
My reading of Nagel here is that an entity having conscious experience means that there is something it is like to be that organism: SIL is a property of the organism, not of its states. ${ }^{18}$ Nagel writes that an organism having SIL is equivalent to its mental states being conscious, not that the mental states themselves have SIL. In the context of his paper, Nagel did not seem to worry about the relationship between an entity's SIL and the mental states the entity had in virtue of it being SIL-conscious: to be an experiencer is to have experiential states. But for us here, this will not do. The issue at hand is how to understand being an experiencer, and one of the questions up for grabs in this context is precisely how we should understand the relationship between experiencers and experiential states. Thus one must not from the start blithely reduce (or conflate) being an experiencer to (with) having experiential states. To see why this is so, it is helpful to trace a bit further the prevalent (reductive) understanding of the relationship between SIL for entities and for states.

For example, consider Block's articulation:

First, consider phenomenal consciousness, or P-consciousness, as I will call it. Phenomenal consciousness is experience; what makes a state phenomenally conscious is that there is something "it is like" (Nagel, 1974) to be in that state. Let me acknowledge at the outset that I cannot define P-consciousness in any remotely non-circular way. ... As I said, P-consciousness is experience. Pconscious properties are experiential properties. P-conscious states are experiential states; that is, a state is P-conscious just in case it has experiential properties. The totality of the experiential properties of a state are "what it is like" to have it. Moving from synonyms to examples, we have Pconscious states when we see, hear, smell, taste and have pains. P-conscious properties include the experiential properties of sensations, feelings and perceptions, but I would also include thoughts, wants and emotions. (Block 1995, 206)

Here Block explicitly addresses SIL only for states, and not for entities. Given that SIL for mental states is coherent only in the context of the more fundamental SIL experiencer, Block must be assuming at the very least a reduction (if not equivalence) of entity SIL to mental state SIL. As another example consider Chalmers' (1995) discussion:

The really hard problem of consciousness is the problem of experience. When we think and perceive, there is a whir of information-processing, but there is also a subjective aspect. As Nagel (1974) has put it, there is something it is like to be a conscious organism. This subjective aspect is experience. When we see, for example, we experience visual sensations: the felt quality of redness, the experience of dark and light, the quality of depth in a visual field. Other experiences go along with perception in different modalities: the sound of a clarinet, the smell of mothballs. Then there are bodily sensations, from pains to orgasms; mental images that are conjured up internally; the felt quality of emotion, and the experience of a stream of conscious thought. What unites all of these states is that there is something it is like to be in them. All of them are states of experience.... If any problem qualifies as the problem of consciousness, it is this one. In this central sense of "consciousness", an organism is conscious if there is something it is like to be that organism, and a mental state is conscious if there is something it is like to be in that state. Sometimes terms such as "phenomenal consciousness" and "qualia" are also used here, but I find it more natural to speak of "conscious experience" or simply “experience." (Chalmers 1995, 10-11)

Unlike Block, Chalmers does explicitly recognize and begin with SIL applied to a conscious organism, both in citing Nagel and in describing "the hard problem." But like Block, he ignores the question of the

\footnotetext{
18 As an anonymous reviewer points out, an organism might be understood as a "state of matter," that is as a relational property of a set of physical components and in this sense, SIL, even understood as a property of organisms, would also be a property of a "state of matter." I will assume here that the "state of matter" that is an organism can be distinguished (ontologically, teleologically, or otherwise) from the component states that compose it.
} 
relationship between SIL for entities and SIL for states, again presumably because a reduction or equivalence is being taken for granted.

These two quotations also indicate how each author will develop their respective reductive accounts of SIL for entities. Block's statement that "the totality of the experiential properties of a state are "what it is like' to have it," leads rather directly to the view that the totality of the experiential properties of the totality of (mental) states a subject has is "what it is like" to be that subject. Similarly, Chalmers explicitly introduces the idea that "what unites" experiential states is that they all have the (second order) property of SIL, and thus presumably SIL for the subject is nothing more than the totality of these experiential states.

But there is circularity lurking here. Block, Chalmers and others explicitly cite Nagel and SIL to ground intuitions, but their arguments focus on mental states with SIL, not subjects. This embodies an assumption that the SIL of mental states are how we get a handle on the SIL of the subject, even though such states are recognized as depending on the subject.

Often in such discussions some circularity is inevitable and unproblematic (e.g., causality and probability) as Block explicitly acknowledges, but lurking here we have a more vicious kind: if it is taken for granted that $S$ having SIL is nothing more than $S$ having mental states with SIL, and if mental states with SIL are simply taken to be the (conscious) mental states of entities with SIL, this can be seen to be problematic. In order to analyze a subject's SIL, it will not do to simply invoke mental states that themselves have SIL and leave it at that; no insight is gained into the SIL of a subject by characterizing it in terms of mental states that themselves have SIL in a way that itself depends on the SIL of the subject. ${ }^{19}$ As long as the explanandum is the SIL of the subject, then to invoke mental states with SIL, unanalyzed except to the extent that they are part of a SIL-conscious entity's SIL consciousness, is to offer nothing at all.

Enter qualia. To avoid this circularity, the SIL of mental states is often ultimately cashed out in terms of the qualitative, usually only though examples - as we see in both Block and Chalmers. The move to qualia is practically inevitable for approaches intent on reducing SIL in this way. It is the way out of the circularity: the SIL of the state is how the red actually "looks" in itself to the subject. This "how" is the intrinsic, nonrelational, nonfunctional aspect of the mental state. A mental state having SIL is understood as shorthand for the state having qualitative properties. Roughly, a subject $S$ is SIL conscious if and only if $S$ has qualia. Here we have explicitly the qualia reductionism described above: SIL consciousness for an entity is simply its having qualia. But there are good reasons to question this.

\subsection{Complicating the Relationship}

How should one think about the relationship between SIL consciousness and qualia? While it is clear enough that they are identical, as we have seen there is a tendency to assume the relationship is straightforward enough to simply pass over, and focus on qualia as the central issue. But an entity's having SIL consciousness cannot be collapsed a priori (pre-empirically) onto its having mental states with second order qualitative properties. In addition to qualitative aspects, subjective experience presents as having structural and relational aspects that are not (obviously) qualitative. Some of these non-qualitative structural features of conscious experience are relational (degree attended to, bodily located, spatial, temporal, etc.) or modal (imagistic, recalled, tactile, visual, etc.) or composite with their own internal relational aspects (self talk, seeing the wall, hearing a fly, etc.) or global (feeling anxious, on edge, drunk, nauseous, angst, euphoric, energetic, etc.). Even assuming that one's SIL at a moment consists of the "states" and "qualities" generally

\footnotetext{
19 Note that it is a philosophical analysis I am discussing here and it is to be distinguished from the empirical research program, which might well be able to accomplish such a reduction.
} 
assumed, this collection is structured by part/whole relationships, temporal and spatial relationships, future/past relationships, modal structure or relationship (cognitive, perceptual, linguistic, conative, affective, etc.) and sub-modes within these, and also within modes and kinds there are relationships like similarity, difference, identity, logical, rational, and causal. In general these non-qualitative structural features of SIL present immediately as having a relational or modal or composite or global character, and not an obvious qualitative character. This is not to assert, however, that these structural features are ultimately and completely without qualitative aspects - this would require a more complete empirical account to help decidebut rather only that such structural features do not immediately present in experience as standard qualia (second order properties of standardly understood mental states).

The nature of qualitative "states" will almost certainly have a deep connection to SIL consciousness, but to assume from the start that they are identical, or that the latter is (actually) reducible to the former, and to frame and constrain empirical inquiry and its philosophical assimilation according to these assumptions is to make the old armchair philosophy mistake of "defining away" solutions and "defining in" intractable problems.

Let us return now to the assumption accepted for the sake of argument, namely, that an entity's SIL consists of all the "states" and "qualities" upon which philosophers generally focus. The move from consideration of entity SIL as a whole to such states and qualities involves at least two important steps. The first is the not unproblematic decomposition of experience as a whole into folk or scientific mental states: there is real debate over whether the various ways in which we carve up our experience into the particular mental states we do are unique, well-defined, scientific, or universal in any sense (Churchland 1981; Stich 1983; Nichols and Stich 2003). Thus the virtually undeniable warrant for the SIL of entities (like us) cannot be assumed to fully carry over when extended to SIL for the more theory-laden and therefore more contentious decomposition of this whole into folk (ordinary or philosophically "reconditioned") mental states. So while it may be undeniable that there is something it is like to be me at a given moment (awake and in front of a stop sign), this warrant does not extend to my having a particular mental state of seeing red that itself has SIL (in some sense appropriate for states). ${ }^{20}$

And second, even if we accept the "decomposition" of our mentality into mental states like those of folk psychology (or a philosophically reformulated version), it is not clear that the SIL of the subject and its decomposition into mental states must line up. Consider the red aspect of my experience of a stop sign. We often talk as if we are able to apprehend and refer to the red aspect ("quale") in isolation, but of course our actual experience of the redness of the sign is not experienced as independent of the other aspects of the experience-aspects like moods, memories, other aspects of our visual field, our olfactory "state," our concepts, and our social connectedness. Current empirical research indicates that the qualitative aspects of experience are in fact dependent on such features. ${ }^{21}$ And there is a strong case to be made on such empirical evidence that this interdependence must be understood as not just a function of other aspects of SIL ("radical

\footnotetext{
20 The "appropriate" sense in this context is (at least) that the SIL of the state (at least in part) accounts for (e.g., explanatorily, causally, determinatively) the SIL of the entity.

21 One vein of such evidence comes from "top-down" influences on perception, of which the work of classical Gestalt psychologists are an early potential example (Wertheimer 1938). More contemporary studies have stressed that in addition to the sensory context, the nature of visual experience depends on a "behavioral" context as well, which includes "attention, expectation, perceptual task, and hypothesis testing" (Gilbert and Sigman 2007, 686). Consider also the bouba/kiki effect (Ramachandran and Hubbard 2001), which reveals the relatedness of the subjective experience of visual (objects) and sounds. The relationship between fear and perception is another such case on which there is clear evidence that the phenomenal appearance of experience may be a function of emotions like fear (Vasey et al. 2012; Witt and Sugovic 2013). Our identification and processing of emotion in faces has been shown to have perceptual "aftereffects" in the processing of emotion in voices (Pye and Bestelmeyer 2015). Finally, in pain studies that have actually targeted the subjective experience of pain (Coghill et al. 2003; Nielsen et al. 2009), results have suggested that the bulk of individual differences in the subjective experience of pain are likely due to cognitive factors like expectations about pain in concert with the subject's emotional state at the time pain is experienced.
} 
multisensory" dependence) but more broadly of one's social and cultural context and conditioning (Allen and Williams 2011). This potentially sweeping dependence might well be because my SIL as a whole, which does contain a red aspect, does not really correspond to any assignment of "SIL" to traditionally construed mental states, and so our talk of the "redness" of this visual state might just be wrong and/or fail to refer at all. This possibility is parallel to how an (American) football team's defense decomposes into 11 individuals, but how its defensive capacity does not decompose in this way: the center run defense may be made up of the inside lineman and linebackers, the run containment made up of the by the ends, linebackers, and cornerbacks, and the free safety may not be part of any specific capacity and yet contribute to all under certain circumstances. In this example, these higher-level (defensive) capacities are not reducible to the individuals that make them up, but instead are composed of different sets of individual team members in particular relationships (to each other and the unfolding environment), with overlap between the members of the sets.

Now does the deep (personal and subpersonal) interdependence of the qualitative aspects of our experience prove that, for example, my red visual aspect is not an individual property of an individual mental state? Of course not, but it does raise the very real possibility that the redness that I subjectively take to be a property of my visual experience of seeing the stop sign, is not at bottom a property attributable to some traditional "mental state" that can be individuated in any reasonable way from other (kinds of) "mental states." But rather, because this subjective "redness" depends on a larger swath of my experience-including aspects of my mood, emotions, memories, attention, proprioceptive awareness and also upon sub-experiential features of my brain/body system-it is better understood as a property of the experiencer (me) as a whole. Of course it may well turn out that for some aspects of SIL, the "swath" of experience upon which it depends might be less than the whole of the subject's experience, but the abundance of empirical work indicating widespread dependence between sensory modalities, beliefs, desires, emotions, and moods make it clear that the "swath" will be much larger and more complex than the standard "mental state" taxonomy favored in philosophical discussions. ${ }^{22}$ Again, the point is that the move to decompose the whole of our entity SIL, both into discrete mental states and into particular well-defined second order qualitative properties of those states, is rife with empirical assumptions, and hence anything but a priori (unlike the fact of entity SIL itself), and to even begin to justify it would require offering an empirically buttressed rationale - and for the most part, there has been little recognition of the need for such a rationale, much less a rationale actually proffered. ${ }^{23}$

\subsection{In Favor of SIL for Entities}

Thus far I have elected to define the SIL predicate as a primitive notion at the entity level. I have insisted on paying attention to the distinction between entity-level SIL and SIL for states, showing how important discussions have simply glossed over the distinction. I have argued that is a mistake to take them to be identical

\footnotetext{
22 Note too the difference between a property being a function of a wider swath and being a property of a wider swath. My personality is a function of my upbringing, but it is still a property of me, not my upbringing. The dependence of aspects of SIL not only on other aspects (at the same level) but also on sub-experiential and on global properties is a more pervasive dependence than can be countenanced by understanding such an aspect of SIL as a property of single mental state but a function of a wider swath. As I will argue below, such pervasive and complex dependence is better understood as a property of the wider swath as opposed to merely a function of it.

23 It should be noted that this holistic dependence (or its possibility) does not entail that it is impossible for a seeing red aspect of experience to occur across a range of total experiences. One needs only that the various total states having a red aspect of the relevant kind enjoy similarity relationships in various ways, and then this same red aspect of experience can be associated with a similarity class of the various total states. Thus two distinct total states could embody the same red experience (because they belong to the same "seeing red" similarity class), despite the red experience's depending on the total state and the total state (almost) never being identical across time. I owe thanks to an anonymous reviewer for help with this point.
} 
or the former to be "reducible" to the latter because the relationship between them is neither obvious nor simply a conceptual matter, that it depends on empirical matters. I will now make an explicit case for taking entity-level SIL as the primitive notion. The case consists of three pieces: (1) a conceptual/introspective argument that locates the original warrant for SIL at the level of entities; (2) comporting experimental results suggesting that qualitative state concepts are not the key to how lay people attribute consciousness to entities; and (3) showing how undue focus on qualitative states as the key to conscious experience obscures empirical approaches to consciousness, thereby helping to "harden" it into a metaphysical question, rather than a tractable empirical one.

The conceptual/introspective component begins with the observation that any consideration of SIL for a state must assume an entity for whom the state has SIL. The SIL of a mental state makes sense only in the (often suppressed) context of a SIL-conscious entity. A mental state that is an experience of the redness of a stop sign does not itself have SIL-there is nothing it is like to be a red experience in this sense, but rather only something it is like to be the experiencer having a red experience, or better yet, the experiencer's SILconscious experience (taken as a whole) at that moment includes a red visual aspect. This conceptual priority is further supported by an introspective inferential priority: what we encounter most immediately when we introspect is a complex whole. And as rehearsed in the previous section, while the complex whole presents as a composite with a plethora of relationships, modes, etc, to assert that it actually consists of the mental states of the folk (or any other philosophical or scientific) framework with accompanying second order qualitative properties is a theoretical assertion that would require further justification to sustain. Thus the immediate and original warrant for the existence of experience is at the level of the experiencer's experience as whole, and any sense of SIL for states requires further (empirical) assumptions that go well beyond the pre-theoretical warrant for the existence of subjective experience.

A clarification and a qualification are required at this point. The sense of "priority" I intend is not threatened by the (correct) observation that in trying to convey to someone new to the debate what philosophers intend by "phenomenality" or "experience" or "qualia" or "hard problem" one often starts with examples like "seeing red." That we often begin such discussions by focussing on a mental state with a qualitative property to make clear the phenomenon we are addressing does not militate against the fact that any such discourse assumes from the start that the state belongs to an experiencer-a subject like us in having a coherent inner subjectivity, that is, having SIL. And further, the inferential claim is that an entity's experience as a whole (SIL) at a given moment is not such that it is obvious that it is actually composed of distinct modalities, states, hierarchies of properties (etc), despite the fact that we do pragmatically so carve our SIL in order to focus on aspects of it. I must stress that the only thing I am taking as clear is that it is not clear from the start that our experience actually consists of the particular distinct parts (modalities, property hierarchies, states) we often employ in talking about experience, that is, any particular way of carving it up will require, if it turns out to be correct, suport beyond the warrant we have for existence of SIL as a whole. That there are SIL conscious entities is the clear starting point. That such experience actually consists of distinct states with higher-order qualitative properties is a conjecture/theory/research program about SIL, perhaps ultimately defensible, but certainly not a "neutral pre-theoretical description" of the phenomenon under investigation. Now for the qualification: despite the fact that I have made a conceptual case for the priority of entity-level SIL, it should not be understood as an a priori metaphysical position, immune to empirical revision. It may turn out that future scientific theory ends up supporting some kind of informational monism (Chalmers) or panpsychism (Strawson) that renders "experience without a experiencer" (proto-experiential properties) a coherent notion-much like how "super-position" became a coherent notion in the context of quantum physics.

Next, the experimental reasons for doubting the primacy of SIL for states come from studies in which folk attributions of experience were tested against the received philosophical versions. These studies suggest 
that, for example, most lay people do not call on the concept of phenomenal consciousness (state-level SIL) in categorizing mental states (Sytsma and Machery 2010), or that the folk understanding of an experiencer does comport with the SIL notion, but does not depend on standard philosophical understandings of qualia (Peressini 2014). (Sytsma (2014) contains a thorough review of these and several others.) The common thread is that the standard philosophical understanding of the concept of phenomenality (qualia) fails (in various ways) to correspond to how non-philosophers conceptualize mental states - and in particular, how they conceptualize "being an experiencer." While experimental work is just beginning on the claim that SIL states are evident in first-person experience, at the very least these results show that it is anything but clear that there is a state level SIL concept at play in how lay people attribute the status of "conscious experiencer" to an entity (Sytsma 2014, esp. 645).

Finally, the qualia reductionism that comes from an undue focus on qualitative states as the key to conscious experience can be seen as facilitating a problematic "bifurcation" in theoretical responses to the question of SIL consciousness: its hegemonic influence explains why many attempts to theorize subjective experience fall into two equally problematic strands. In rough terms the strands are (1) the over-mystifying moves of the "hard problem" and panpsychism theorists, and (2) the "over-simplifying" moves of representationalists. When the problem of phenomenal experience is understood as collapsing into the question of qualitative properties of mental states few options are open: one either offloads SIL into a non-physical (informational or proto-experiential) world or unceremoniously dumps it into the physical word, thereby throwing the real issue of experience "out with the bathwater." Prominent examples of the first move include McGinn (1991, Ch. 1), Chalmers (1995, 1996), Strawson (2006) and perhaps Tononi (2008), while the second approach is represented by thinkers like Dretske (1995), Tye (1995), Rosenthal (2005), and Kriegel (2009).

While I do think it is a real defect of "qualia reductive" approaches that they facilitate hardening or ignoring the very real (but not necessarily metaphysical) problem of consciousness, this rough schema is not intended as a deep diagnosis or exhaustive categorization of philosophical accounts of consciousness. Some prominent accounts do not fit perfectly into either camp. For example, Owen Flanagan's (1992) account skirts this bifurcation in that he does not collapse SIL onto qualia traditionally understood, nor does he dismiss the qualitative aspect of experience. Instead he employs a distinction between informational and experiential sensitivity, which is akin to the "metaphysically thin" sense of qualia I develop below (Sec. 4.2). But because he does so in the standard reductive context of SIL for states, he ultimately fails to address the problem on its own terms. (See Levine (1994) for critical details.) Other accounts do actually address the relationship between SIL for entities and SIL for states. In interesting ways Tononi's integrated information approach is hard to categorize, as is Tim Bayne's $(2007 ; 2010)$ account, which grows out of important but distinct unity of consciousness considerations. I consider these less reductive approaches and the general question of the relationship between SIL consciousness and qualia in the next section.

\subsection{Less Reductive Understandings}

The few discussions that do mention the move from SIL for entities to SIL for states still generally collapse the former into the latter. For example, Tononi (2008), who develops an intriguing empirical account of the quantity and quality of SIL consciousness based on integrated information, fails to carefully distinguish between SIL conscious entities and conscious qualitative states. Tononi's account, confirmational details, and philosophical impact have been obscured by the lack of clarity around SIL and the qualia reductionism described above (Peressini 2013). Without getting into the details here, the upshot is that after the dust settles and terms are straightened out, the integrated information account is best thought of as an account of 
the qualitative aspect of an entity's experience rather than directly constituting an account of consciousness at the entity level in the SIL sense. It is only because SIL consciousness is being implicitly equated with qualia that Tononi takes the further step to claim that conscious experience simply is integrated information (Tononi 2008, 217). Such conflation both overstates and understates the import of his empirical contributions (Peressini 2013, sec. 3.1).

As described above, early on in his book, Kriegel (2009) dismisses the SIL approach to the mystery of consciousness, opting instead for a state-based approach in which he does distinguish between qualia and a certain kind of subjectivity. Kriegel argues that conscious mental states have at least the following two aspects: a qualitative character and a "for-me" or subjective character. When I experience a clear blue sky the experience has a qualitative character (q-character) of "bluishness" and a subjective character (scharacter) of "being mine" in that intimate first person subjective sense. He argues that the problem of the $\mathrm{s}$-character is the more serious one with respect to consciousness, though he seems friendly to the idea that both may be responsible for the "mystery of consciousness." Kriegel's account of the q-character is essentially representationalist (like Rosenthal's) and his account of the s-character turns out to be a variant of the Higher Order approach that equates it with being the object of a representation (again like Rosenthal's), namely of the state itself. (Rosenthal requires that it be the object of a higher order thought.)

Tim Bayne does explicitly discuss the relationship between SIL for entities ("creatures" in his terminology) and states. In Bayne (2007, 2), he dismisses without argument understanding the distinction as between kinds of things (states and entities) that have SIL. Instead he suggests that it be understood as a relationship like that between a determinable and a determinate, e.g., colored and red. Accordingly, an entity's SIL consciousness is made up of its determinate qualitative states in just the way that an object's being colored involves nothing more than its being red. In a later work (Bayne 2010, 8), he again equates entity consciousness with "the most general (or 'determinable') property associated with consciousness: the property of being phenomenally conscious." ${ }^{24}$ But as I drew out above, our SIL is more structured than a simple determinable. The comparison with the simple determinable "being colored" could not be right. A better comparison for the relationship between SIL and qualia is being a colored shape (in two dimensions) and being a red shape. Being red is part of being a determinate colored shape, but by itself does not determine the determinable. There are multiple ways to be a red shape (e.g., red triangle, red square, etc.); further structural features need to be pinned down in order to have a determinate colored shape. So too, specifying an entity's qualia would seem to fail to determine its full SIL-conscious field. ${ }^{25}$ But even this is too simple.

A more plausible way of thinking about the relationship between SIL consciousness and qualia is by likening it to the relationship between an organism's fitness and its particular physical makeup. An organism's fitness is a property of it as a whole-its sharp teeth or long neck do not have fitness values of their

\footnotetext{
${ }^{24}$ Here Bayne understands entity consciousness as being a determinable that takes two kinds of determinates: background conscious states and specific conscious states" (p. 8).

25 Bayne's (2010,7-8) later understanding of entity consciousness as having two kinds of determinates (background and specific conscious states) does come closer to accommodating the point I am making here. He conceives of the background state (normal wakefulness, dreaming, hypnotized, etc.) "as best thought of as regions in a complex state-space, the parameters of which determine both the selection and functional roles of the subject's specific conscious states (or 'contents')" (p. 7). This seems quite right as far as it goes-it nicely captures how "specific conscious states" are deeply relational (dependent upon the background state) for their "content." But again, I am arguing that this construal is not relational enough: aspects of our SIL (its "states") are not just dependent upon a (single) background state like wakefulness, but rather upon many, many other aspects ("states" both background and specific) and other subpersonal and experiential states. One might object to this, arguing that while one's SIL may be constitutively dependent on (e.g.) various modes of (sensory) experience, SIL seems only causally dependent on subpersonal states. And while this may or may not be clearly the case (i.e., SIL, if an "emergent" phenomenon, may well cut across this distinction), this distinction is less relevant to the issue of SIL's holism than it is to the unity of SIL. This is because holism questions, which in the sense here are especially concerned with decomposability, may well be constrained by causal dependencies. Bayne, of course, is more focussed on the unity question; his examples seem fine for that purpose.
} 
own. Scientists may speak of the fitness of a trait or allele, but this is a derived sense of fitness. The fitness of a trait or allele is defined in terms of the average fitness of the organisms in the population possessing the trait or allele. And importantly, there is no sense in which the organism's fitness can be reduced to or determined by its traits/alleles because, while the organism's fitness does depend on such things, it is only the organism as a whole that survives and reproduces and hence can have a (non-derivative) fitness value. In addition, the fitness of an organism depends on how its traits are related to each other and to its environment. And at this point we have left the determinable/determinate understanding far behind. ${ }^{26}$

Thus we are left with no real rationale for understanding entity SIL as reducible to or analyzable in terms of SIL for mental states-and plenty of reason to think otherwise. Still it must be conceded that there is some plausibility to the idea that SIL requires at least some qualitative features in one's field of experience, though it is surely too strong to understand this as entailing that SIL consciousness actually does (and must) consist of precisely the discrete mental states of folk psychology that themselves have "qualitative" properties. To maintain that SIL conscious experience, which presents experientially as an integrated whole, is exhaustively decomposable into discrete "states" goes well beyond the original introspective warrant of our own SIL and well into Cartesian transparency and infallibility. The Nagelian "reasoning" that we ourselves and many other (kinds of) entities are experiencers is highly warranted if anything is, but the further claim that our experience is uniquely decomposable into the discrete mental states of our folk system and that these states have a special property of their own that is responsible for there being "something it is like" to be in them would require much more clarification and justification than advocates have to offer. ${ }^{27}$ The alternative approach being advanced here is to operate from an understanding (naturalistic, if you will) that philosophical work on subjective experience must incorporate, be incorporated with or be continuous with scientific work, and hence very little can be held fast on sheer a priori grounds. Thus even what has been taken as part of the fixed pre-theoretic explanadum (e.g., psychological state taxonomies) has to be seen as revisable in light of ongoing dialogue with empirical science.

But what about the more moderate position that SIL ought to be understood as necessitating at least some qualitative aspect in one's field of experience? That is, does SIL consciousness require qualia in some sense? Even this does not seem obvious. Phenomenological conservatives (e.g., Peter Carruthers 2005, Michael Tye 1995) maintain that not all our mental states have (their own) phenomenal/qualitative components, e.g., cognitive and higher-level perceptual states. And perhaps less contentiously, Galen Strawson (2010) argues that in certain meditative moments (fortuitous or developing out of a disciplined meditative practice), one

\footnotetext{
${ }^{26}$ As suggested by both this comparison and Bayne's astute description of entity (creature) SIL consciousness as involving "regions in a complex state-space," SIL consciousness might well be best thought of along the lines of complex dynamical systems theory (Varela 1995; Freeman 2000; Thompson et al. 2005; Silberstein and Chemero 2012; Olivares et al. 2015). One of the more compelling aspects of such approaches is how complex dynamical systems theory captures dynamical features of both the third person brain/body system and first-person phenomenological experience. On this view there is a rich, complex, dynamical structure to one's SIL: it is not merely a heap-like assemblage of qualia, nor is it a "space" that neatly decomposes exhaustively and exclusively into subspaces (perceptual, cognitive, conative, affective, etc.) that in turn further decompose into states neatly tagged with their qualitative property(ies). Nor of course, is it plausible at our current juncture even to think of SIL as neatly divided between qualitative aspects and structural or relational ones, since it seems very unlikely that the deep interconnections between "levels" (micro, meso, macro, among others) of organization of the brain and its dynamical nature afford any such "neat" characterizations of SIL, even at the subjective, first-person, phenomenological level. On this approach, any "carving up" of SIL must be done in a conversation with empirical theory so that the conceptual and empirical work reciprocally inform and revise each other. And so any "hard" metaphysical problems that depend on a priori ways of "carving up" of SIL space (e.g., psychological states with second order qualitative properties) cannot be taken as anything more than a temporary scientific lacuna, a philosophical non-problem, or some combination of both.

27 In particular, this second claim cries out for clarification as to why one should think SIL requires discrete mental states in all experiencers; whether we really have such discrete states ourselves; why, even if we do have precisely the states of folk psychology, the property of "what it is like to be" neatly breaks along just these lines; why SIL should be a property of the mental state itself as opposed to a property of the "system"; what justifies the reductive or decomposable assumptions it depends on; what sort of truth is it-metaphysical? Empirical?
} 
may enter "... a state that has no particular content beyond the content that it has in so far as it's correctly described as awareness or consciousness of the awareness or consciousness that it itself is ..."(p. 293). If either of these views are coherent, then it is conceptually possible to have a SIL conscious entity without qualitative aspects. $^{28}$

To summarize, I have argued in Section 3 that an inquiry into subjective experience in the sense of SIL is best begun with a recognition that it is first and formost entities that have SIL, and that to reduce or decompose entity SIL into states with SIL involves substantial (and largely ignored) theoretical commitments that go well beyond what is warranted independently of empirical theory. It is the tendency to ignore this decomposition step that tends to lead theorists to an untenable reduction of entity SIL consciousness to qualia (traditionally conceived) - often with an attending commitment to some form of a conceptual link between entity SIL consciousness and qualia. I will argue further below that neuroscientific results provide another kind of reason to doubt a conceptual link between SIL consciousness and traditionally conceived qualia. But first I outline a proposal for a holistic understanding of SIL.

\section{A Holistic Alternative}

The holistic approach to being an experiencer that I propose begins with the SIL concept as applied to an entity and does not insist a priori on the reduction or equivalence of SIL for entities (heretofore simply SIL) to some sense of SIL for mental states. Again, the motivation for this is that (1) the clear pre-theoretical warrant is for SIL entities, not the derivative and more contentious theoretical SIL for mental states, and (2) such an approach is philosophically more conservative, i.e., decides less from the "armchair," thereby leaving the theoretical space more open for empirical contribution.

Such a holistic account, in resisting the reduction to qualia, need not (and should not) eschew altogether the notion of "something it is like" for states. One is owed an explanation of the widespread (at least among philosophers) notion of there being "something it is like to see red." On the account I develop below, such notions will be understood in terms of a qualitative aspect of the whole of the subject's SIL, rather than as traditional philosophical qualia, that is, as second-order properties of mental states.

In the sections below I develop the holistic account, detailing how it avoids the reduction to qualia, how it replaces the standard philosophical notion of qualia with qualitative aspects of the SIL, and finally how it is supported by and reciprocally supports empirical work.

\subsection{Experiential Holism}

The general idea behind experiential holism is that the various features of experience, standardly understood reductively as properties of mental states, are instead properties of the entity's subjectivity or SIL as a whole and not necessarily analyzable as properties of individual states. ${ }^{29}$ This is hardly an exotic position: it is the same non-mysterious sense of irreducibility at play in why the fitness of an organism cannot be analyzed in terms of the fitness of its parts or why the viscosity of a fluid cannot be understood in terms of the viscosity

\footnotetext{
28 Such an entity might even have at least some of the structural features of a SIL conscious experiencer (unity, aspects/parts, temporal progression, etc.) and perhaps even perceptual, affective, and conative states and yet fail to have qualitative aspects at all.

29 Alternatively, Ole Koksvik $(2014,110)$ understands experiential holism modally as asserting that "local conscious experiences would not be conscious if they were not components of a global experience." See Lee (2014) for discussion of further kinds of holism and atomism regarding experience. Also, I take it that whether "seeing red" can in the end be fully attributed to a subsystem, like visual system, is an empirical question. Again my case here is for resisting the a priori carving of the explanandum into the standard mental states with second-order phenomenal properties.
} 
of the molecules that make it up, or why the amplitude modulation (AM) waves of the brain cannot be understood as AM waves of the individual neurons that make it up. In all these cases, while the property in question is determined by properties of its constituents (at various levels) and their relationships to each other and to the broader physical environment, the property itself is not properly attributed to its constituents, and consequently not straightforwardly reducible in the way that, say, the mass of a body is reducible to the mass of its constituent parts. ${ }^{30}$

The sense of irreducibility I am employing here then is not the more familiar sense employed in the standard debates about whether the mind is reducible to the brain, whether thermodynamics is reducible to statistical mechanics, or whether mathematics is reducible to logic. In these debates the question centers around whether entities and properties at the higher level can be taken (in some sense) to be nothing more than distinct entities and distinct properties at a lower level. Instead, the question I am pointing to is whether SIL for an entity is "reducible" to the SIL of the states that make it up. The parallel questions in standard debates would be whether the mental properties of the mind (e.g., belief) can be "reduced" to the (same) mental properties of the brain cells that constitute it, whether thermodynamic properties of a gas (like temperature) can be "reduced" to the (same) thermodynamic property of the (individual) molecules that constitute it, or whether a mathematical property (e.g., continuity of a function) can be "reduced" to the (same) mathematical property of the sets that constitute the mathematical entity (function). It should be clear that these are not reasonable ways of understanding the rich and interesting questions of reducibility in philosophy of mind, science, and mathematics. But this is precisely the sort of "reduction" that is generally taken for granted in the context of SIL consciousness, and the sort against which I am arguing.

A more perspicuous way of putting the point is that SIL for an entity is not straightforwardly analytically decomposable into SIL of the states that (putatively) make it up. ${ }^{31}$ Call this $d$-reductionism. ${ }^{32}$ When pressed on this assumption, however, advocates of d-reductionism often demur, explaining that it is only at the level of a priori conceptual relationships that entity SIL is nothing more than "the sum" of SIL bearing states of the entity, and that of course the SIL states do not by themselves "hang together" in such a way as to generate a SIL conscious entity-it is an empirical question as to how the physical system works to instantiate both the SIL states and the SIL entity. My response (and point in this paper) is that far too much is being decided and constrained at the (arm chair) level of a priori conceptual relationships by such dreductionistic assumptions-too much in the sense of more than is warranted by the pre-theoretical "data" and more than can plausibly be claimed as benign or neutral starting assumptions with respect to empirical inquiry. The kind of holism being developed here is one that can be understood as running contrary to this kind of d-reductionism.

The following example should help illustrate it. Consider a play, say, "Romeo and Juliet." In the context of this play, a certain character $M$ may behave mercurially and if one wants to understand why there is this mercurial behavior going on, it will not do simply to investigate the properties of the actor playing $M$; instead one must first understand the play itself, both how it goes from beginning to end and the principles (narrative, moral, aesthetic, practical) under which it is a cohesive whole, including the mercurialness of

\footnotetext{
30 For a detailed account of a kind of irreducibility (or emergence) as non-aggregativity see Wimsatt (2007, Ch. 12).

31 As a reviewer points out, a possible objection to this might be to argue that our global conscious state does have definite color experience components, auditory components, etc. But notice that the (putative) fact that our global SIL state has modal aspects (e.g., auditory, visual, etc), each with perhaps its own (apparently) distinctive contributions to the global SIL does not entail that SIL experience is actually comprised of these distinct SIL components-any such SIL aspect cannot be known (pre-empirically) to belong (as a property) to the particular mode alone-it may well be a property of multiple modes and/or more global aspects like emotions, expectations, cognitions, etc.

32 As I argued above, this view about the analytic decomposability of entity SIL in terms of state SIL often leads rather directly to a more orthodox form of reductionism, namely, the reduction of entity SIL to qualia when one adds the additional assumption that SIL for a state is simply its qualitative properties.
} 
its other characters and perhaps even other non-character features (e.g., weather, lighting). While this play is composed of particular actors, among many other kinds of things, it makes no sense to treat the actor playing $M$ as if the mercurialness were a property of him/her and to try to figure out why s/he is that way. As is clear, the mercurialness in question is not an intrinsic property of the actor, like perhaps the actor's vanity is. ${ }^{33}$ Instead the mercurialness s/he displays is essentially a particular kind of relational property, one that is deeply dependent upon (among other things) the nature of the play itself, which is a global or higher-level or holistic property. One must understand the mercurialness displayed by the actor playing $M$ as a property of the play itself. And while it is true that the play can be thought of as being composed of characters (among many other things at many other "levels") that display certain features such as mercurialness, these features can be understood only in the context of and at the level of the play as a whole. Properly speaking, they are not properties of the actor (or anything else "below" the level of the play) but of the play itself. Of course there is a sense in which the mercurialness may apply to one actor and not another. But this does not support a non-relational sense of mercurialness, rather only a kind of relation complex enough to include/exclude different aspects of the whole. Notice too that properties like mercurialness may be thematically embodied by the play itself and explored in its non-character structures as well as, e.g., in the weather or the lighting or rhythm of the action or way the scenes flow, etc.

In a similar way, the qualitative red that is an aspect of my SIL at the moment, and is associated with my seeing a stop sign at this moment, is no more a property of my mental state of seeing the stop sign than the mercurialness is of the actor playing the part. It is best thought of as a property of the SIL experience as a whole, since there is reason to think it is dependent upon many other aspects and properties (at various levels including a global level) of the experience/experiencer, and is in this sense a "holistic" property. And as with the mercurialness of the character, the holistic relational nature of this "red" qualitative aspect does not preclude it from "belonging to" one aspect of my experience (e.g., a spatially specific and/or modally specific aspect) and not others. To be clear, this comparison of SIL experiential holism with the mercurialness of a character in a play is not intended as an argument in itself, but rather as part of an argument that involves showing how SIL can be framed in a way substantively different from the received (non-holistic) version. I will argue below that there is additional reason to think that this holism is on the right track because it squares better with a larger array of empirical work.

I use the more neutral term "aspect" for such properties of SIL. These aspects of SIL may ultimately be deeply relational global properties, despite appearing relatively intrinsic and local from subjective perspectives. Thus, instead of " $S$ is experiencing a red quale at time $t$ " we have "S's SIL at time $t$ includes a red qualitative aspect." The point of this is more than terminological: "qualia" has a standard understanding as a second-order phenomenal property of a mental state, and its grammatical status further fosters the reification of such local intrinsic properties. The term "qualitative aspect" is intended to embody the more neutral position of identifying a (kind of) feature of our SIL without prejudicing its status pre-empirically. ${ }^{34}$ In this way holistic qualitative aspects (as opposed to qualia) do not lend themselves to a Chalmers-style "hardening" of the problem of experience because they are recognized from the start as (at least potentially) relational (cf. Section 2 and the explanatory gap discussion).

Importantly, the holistic approach allows one also readily to countenance the structural features of SIL described in Section 2. Recalling that discussion, some include its unity; a general temporal ordering; a sense

\footnotetext{
33 I am happy here to understand "intrinsic" in the weaker, relative sense of some thinkers in the qualia discussion in which something need only be non-relational at the particular level under discussion to be intrinsic. In this context, the psychological and other personality characteristics of the individual actors in the play would be intrinsic relative to the level of the play itself.

${ }^{34}$ Recall that not only is the ultimate physical/metaphysical status of "qualitative aspects" being left open and sensitive to scientific progress, but so too is the notion of SIL itself, which on this account may turn out to refer to something radically different from what we might guess from our pre-theoretical acquaintance with it.
} 
of the present that involves a sense of the immediate past (retention) and immediate future (protention); its falling into different modes (cognitive, perceptual, linguistic, conative, affective, etc.) and sub-modes within these (e.g., imagistic, recalled, tactile, visual, etc.); composite aspects that involve multiple structural features (self talk, seeing the wall, hearing a fly, etc.); global (feeling: anxious, on edge, drunk, nauseous, angst, euphoric, energetic, etc.); and others that present immediately as having an essentially relational character (degree attended to, bodily location, spatial location, temporal location, etc.). On the holistic approach, not only are pre-theoretical d-reduction assumptions avoided, but the holistic framework also leaves room for and thereby calls for consideration of the fullness of SIL. Within this holistic perspective the all too common move to ignore the pre-theoretic primacy of entity SIL and instead focus on the more traditional and theoryladen "SIL-conscious" mental states can immediately be seen to be misguided because it obscures the deeply relational-structural nature of aspects of entity SIL that are grounded in the dynamic and holistic nature of experience as experienced and in the dynamic and holistic nature of the mind-brain-body system as theorized empirically.

This holistic approach can also readily countenance the various other kinds of unity present in experience. Bayne (2010, Ch. 2) rightly points out that there are different conceptions of the unity of consciousness as well as different senses of it. In his discussion he concludes that the relevant kind of unity in the context of consciousness is that subjects (necessarily) have a "phenomenal field" or "total conscious state" that subsumes all of the distinct conscious states that they enjoy at a time in a mereological part/whole relationship (17): a subject's total conscious state subsumes each of the subject's specific conscious states and is not itself subsumed by any other conscious state (15). While this is also an important kind of holism, it is not the kind I am employing. The point to notice is that the "total conscious state" to which Bayne refers is understood as consisting of component states that themselves have SIL, which is in keeping with his view that the relationship between entity and state SIL is that of the relationship between a determinable and its determinate-or at the very least a priori analytically decomposable. Hence on Bayne's model, the relationship between SIL entity consciousness and SIL for states is understood along the lines of mass, rather than fitness, which is not the holism I am advancing. ${ }^{35}$ Indeed, this should make it clear that understanding consciousness as a unity (in Bayne's sense) is not the same as understanding it holistically (in my sense), though they are of course complementary.

To push the comparison a bit further, consider how Bayne's mereological account and SIL holism deal differently with the need to account for (what at least appear to be) "parts" or "aspects" of the unity/whole. As we have seen, on Bayne's mereological model the "parts" are in fact proper parts: a subject's total conscious state is composed of conscious states. On the holistic account, a subject's total conscious "state" (SIL) is not assumed to be composed of (sub)states that are themselves conscious (have SIL): the red stop sign in the right half of my visual field is an aspect of my SIL at the moment, it is not a "substate" of my SIL itself with "SIL." So again, it should be clear that Bayne's account is not employing the same kind of the holism developed here because for him the SIL of the whole does consist of an "appropriate sum" (mereological union) of its SIL-bearing parts, whereas SIL holism resists the pre-theoretical assumption that an entity's SIL is decomposable into parts/states themselves with SIL.

It is interesting that in the end Bayne (2010) favors a "creature-based" methodology for the "nondifferentiating correlates of consciousness" (247), which he identifies with the "core correlates" of consciousness. ${ }^{36}$

\footnotetext{
35 Again, the point of the mass vs. fitness comparison is that the mass of a composite body is simply the sum of the masses of it components, but the fitness of an organism is decidedly different in that (1) the fitness of an organism is in all ways prior to the fitness of any of its components (traits), and (2) the fitness of an organism cannot be analytically (or otherwise, e.g., methodologically) decomposed into or reduced to the fitness of it components (traits) because of the deeply (and widely) relational nature of fitness.

36 For Bayne (2010, 240), differentiating correlates are the "enabling” correlates. See also Bennett and Hill (2014) and Watzl (2014) for discussions of holism in the context of the unity of consciousness question. Many of these and related issues are also taken up in Hill and Bennett (2014).
} 
Bayne argues that his "quilted" framework approach for empirical theory building is "a plausible holism" (244ff), primarily because it is well situated to accommodate the unity of consciousness. The SIL holistic approach is naturally friendly to such methodological holism, and like the quilted approach, it is certainly not trying to legislate a priori against content (or "state") based empirical approaches, but it does resist d-reductive assumptions earlier in the process, i.e., in the pre-empirical carving up of the explanandum.

Resisting what Bayne calls atomism or the related d-reductionism developed here at the pre-theoretic level of the SIL phenomena is not to legislate a position that cannot be overturned empirically-it certainly allows for that possibility. Rather it is embracing a more conservative philosophical approach, deciding less from the pre-theoretic armchair.

\subsection{Philosophical Qualia vs. Qualitative Aspect}

As sketched above, SIL holism resists pre-empirically associating the qualitative aspects of our experience with special second order properties of mental states, i.e., qualia. As I argued above, conceiving of SIL experience as composed of such qualia is not only unwarranted pre-empirically, but also facilitates either a short-circuiting or a hardening of the currently real but not necessarily insurmountable explanatory gap between scientific accounts of the brain/body system and SIL (Sections 3.3 and 4.1). It is a mistake to ignore the more fundamental notion of an experiencer and/or ignore the rich and complex question of the relationship between SIL at an entity level and the (derived) SIL of mental states because in particular, it fails to leave room for the possibility of the explanatory primacy of certain higher-level properties of collections of such "states," which is precisely what structural properties are in the sense detailed above. ${ }^{37}$

SIL holism explicitly prevents lapsing into some sort of qualia reductionism (construing the main explanandum in terms of qualitative properties of mental states), thereby "hardening" the problem into one that is empirically intractable. The holistic framing associated with qualitative aspects (instead of qualia) eschews framing the problem of experience in terms of second order phenomenal properties (qualia), employing instead phenomenal properties of experience as a whole (aspects), and this kind of property, while still "mysterious" based on what we currently know about the brain, cannot be seen immediately (by its very conception) to be empirically intractable - and in fact some of the field theory, integrated information, and systems theory accounts look promising with respect to experience construed holistically. Thus SIL holism countenances a mystery of consciousness or explanatory gap (as any realistic account should), but does not "harden" the problem of consciousness into an empirically intractable metaphysical problem (recall Section 2 and the explanatory gap discussion) ${ }^{38}$ What is more, there is experimental work suggesting that for purposes of characterizing the explanandum, there is reason to think that we need only a "metaphysically thin" concept of the qualitative aspect of experience, rather than philosophy's traditional full-blown metaphysical conception of qualia (Sytsma and Machery 2010; Peressini 2014).

This traditional sense of qualia, "m-qualia" (metaphysical), is by conception if not definition what is left over after all functional/relational properties of the brain/body system are explained. The metaphysically thin version is the characteristically "red" (or whatever) aspect of SIL, but is understood as fully determined by and inseparable from the physical system composing an experiencer. This "p-qualia" (for "physical" or

\footnotetext{
37 This point is similar to that of the methodological holists in the debate between holists and individualists with regard to social science (Zahle 2016), and more close to home, how biological complexity may require certain kinds of "holistic" perspectives (Mitchell 2003, 2009)

38 A qualia advocate might attempt to mitigate this advantage by moving away from traditional philosophical qualia as private, (effectively) ineffable, and (relatively) intrinsic, but to do so is to move to that extent toward holistic qualitative aspects, and while it is an interesting question as to precisely at what point one's conception ceases to be "qualia" and becomes "qualitative aspect," it is sufficient for the purposes here that there be clear examples at both ends.
} 
"pholk") has some of the properties of m-qualia: it is qualitative in that it concerns how the experience actually presents to the subject-its "raw feels" (Tolman 1932; Farrell 1950), it is private/perspectival, and it is practically ineffable. But p-qualia is understood as ultimately tied to the physical. ${ }^{39}$

My notion of a "qualitative aspect" (say redness) can be thought of as something like p-qualia. As such it is distinct from m-qualia in that it is metaphysically thin, but it is different in another way because it is not a property of a mental state, but rather a property of SIL experience as a whole. And it is this whole, which includes among many other things its qualitative aspects, that must be acknowledged, embraced, and explained by a scientific account of experience. ${ }^{40}$ In particular, if some of the holistic scientific theories, e.g., integrated information theories (Tononi 2007, 2008), thalamic dynamical core (Tononi and Edelman 1998; Edelman and Tononi 2000), neurodynamical systems theories (Freeman 2000), global workspace (Baars 1993; Dehaene and Naccache 2001), turn out to be correct, then trying to map our folk mental states with their qualia onto such an account will be futile at best, and quite possibly an outright hindrance to scientific progress. ${ }^{41}$ What is more damaging —at least to philosophy's role in the shared inquiry—is that such dogged and dogmatic pre-empirical commitment to some version of decomposable qualia reductionism, which fuels and is fueled by the consequent illusory perception of the empirical futility and "hard" intractability built in to the perspective, marginalizes (much needed) philosophical contributions. In the end the putative intractability of SIL because of "hard problem" construals that embed this qualia reductionism militate not against science's ability to help address the philosophical problem of experience, but rather against the d-reductionistic framework of which the intractability can be seen to be an artifact, since perfectly viable holistic alternatives are available.

It is worth detailing how this proposal is distinct from Kriegel's distinction between the subjective and qualitative characters of experience. First, Kriegel begins his theorizing from SIL conscious mental states, distinguishing two of their characters: the subjective ("for me-ness") and the qualitative ("red-ishness"). Thus from the start his proposal is distinct from experiential holism which rejects the attribution of SIL to mental states, and so the very "things" that have "subjective" or "qualitative" characters are different. Additionally, Kriegel (2009) maintains that a full philosophical account can be given for the subjective character and the qualitative character. He offers a fairly standard representational account of the qualitative character and an original self-representational account of the subjective character. On the SIL holistic account, not even the distinction itself, much less the nature of something like s-character and q-character can be given a defense prior to or independent of empirical theory. ${ }^{42}$ What Kriegel outlines as the primary source of the mystery of consciousness, the question of the s-character of experience, lines up most closely with SIL itself and, as argued above, this cannot be analyzed and circumscribed from the armchair to be nothing more than

\footnotetext{
39 This conception of p-qualia is not unlike Dennett's (1988) replacement for the m-qualia he attempted to “quine.” Dennett proposes PIP (phenomenal information property) detectors, following Peter Bieri. His provocative suggestion meshes rather well with a recent prominent scientific account of consciousness and qualia, the integrated information account (Tononi 2008); see Peressini (2013) for philosophical discussion.

40 The qualitative aspect of experience understood as part of SIL holism and along the lines of p-qualia may or may not end up being representational. It could be that the qualitative aspects of SIL supervene on integrated information (Tononi 2008) in which case it will be an essential part of a representational aspect of experience, though not representational itself, which fits with this holism, since accordingly it is not proper parts (states) of SIL experience that represent, but rather that experience as a whole has representational aspects.

41 That is, folk mental states may well not turn out to be the "joints" at which a scientific account of experience "carves things." See Bayne (2010, Ch. 10) for compelling reasons to think that empirical considerations and the unity of consciousness strongly favor such holistic or "quilted" accounts.

42 While he does explore possibilities, Kriegel (2009, Ch. 2, Sec. 3) officially leaves open the precise relationship between the s- and q-character, allowing (perhaps) for aspects of it to have empirical resolution. Nonetheless, Kriegel does in an appendix offer a standard (a priori) philosophical argument that SIL cannot merely be q-character in a way that separates it from s-character. And further, his framing and carving of the problem into s- and q-characters that are "psychologically real" and "conceptually distinct components of phenomenal consciousness" (p. 52) does not seem based in or open to revision via empirical results.
} 
the problem of the "for me-ness" of mental states. Instead, exactly how the whole that is SIL with all its aspects (qualitative, structural, representational, etc.) gets "decomposed" (in the sense of determining the different features of the brain/body system that give rise to it) has to be left open philosophically as it is dependent upon empirical results. Whether and the extent to which the "for me-ness" and "red-ishness" of experience are really distinct depends on features the brain/body system that compose them and will be answered empirically, if at all. ${ }^{43}$

A final virtue of treating "qualia" as the qualitative aspect of experience understood holistically is that it is much more amenable to encompassing neglected non-sensory "qualitative states" like emotions, moods (especially undirected moods like feeling restless or energetic), and more general "experiential tones" (Seager 1999, 95) that are most noticeable, for example, when everything becomes decidedly pleasant after a margarita or two. Such qualitative aspects of experience can have their natural place in a SIL holistic framework and do not have to be "contorted" to fit into a representational or sensory driven taxonomy of mental states. Instead such questions can be left to or at least answered on the basis of mature empirical theory, if and when we have it.

In a similar way, the standardly construed philosophical question of whether cognitive "states" (e.g., believing the Pythagorean Theorem) have SIL is rejected on SIL holism: the analogous question in the holistic framework, whether cognitive aspects of a subject's SIL also have a qualitative aspect of their own, clearly cannot be answered until the connection between these features of SIL and the brain are embedded in a mature scientific account. Such disputes cannot be resolved a priori, independently of what we know or will come to know scientifically about the brain-body system.

\section{Concluding Remark}

So where does experiential holism leave the "hard problem" and the "explanatory gap?" The holist approach to SIL consciousness dissolves (not resolves) the "hard problem" construal of experience because it exposes the fact that such a construal depends on a step that involves distributing the undeniable existence of SIL for entities onto the entity's mental states as SIL-experiential properties of the states construed along the lines of traditional metaphysical qualia ... and once this step is accepted, the "hard problem" is legislated into existence. By exposing the "freight train" of unwarranted and unnecessary "baggage" loaded into this step, and by offering a viable alternative without such "baggage," experiential holism releases us from a preempirically calcified "hard problem." And it does so without short-circuiting the very real explanatory gap that currently exists, but also without elevating it into an empirically intractable, transcendent metaphysical gap, recognizing it instead as what is most likely only a temporary lacuna in our scientific understanding.

I have argued for resisting the reduction of SIL consciousness to qualia as facilitated by the decomposition of an entity's SIL consciousness into states with SIL, and instead for viewing the SIL consciousness of a subject as a holistic property that does not (a priori) reduce to qualitative mental states. On such a holistic account, while there is something it is like to be me seeing red, I have no mental states with the property of there being something it is like to be in them. Thus it makes no sense to maintain that I have a "seeing red" state with something it is like to be in it, and so in this sense, there is in fact nothing it is like to see red.

\footnotetext{
43 And again, if the dynamical systems approach to the brain/body system turns out to be correct, then the deep interconnections between dynamical "levels" (micro, meso, macro, etc.) of organization of the brain will undercut any such "neat" philosophical characterizations of SIL—even at the subjective, first-person, phenomenological level, that is, it will if the philosophical characterization takes empirical theory to be in any germane to such discussions.
} 
Acknowledgements My thanks go out to the anonymous reviewers for this journal-the paper is much improved because of their comments. A much earlier version of this paper was presented at the Eastern APA Meeting 2012; I am grateful for the comments and suggestions I received from participants there. Also, key parts of this work were done on sabbatical in Berlin 2012-13; I thank Michael Pauen and the Berlin School of Mind and Brain for support and comments. Finally, I thank members of my graduate seminar at Marquette University (Spring, 2014), Jered Janes, my RA, Clark Wolf, and Jodi Melamed for helpful comments and other assistance.

\section{References}

Allen, M. and G. Williams (2011). Consciousness, plasticity, and connectomics: The role of intersubjectivity in human cognition. Frontiers in Psychology 2(20), 1-16.

Baars, B. J. (1993). A Cognitive Theory of Consciousness. Cambridge: Cambridge University Press.

Bayne, T. (2007). Conscious states and conscious creatures: Explanation in the scientific study of consciousness. Philosophical Perspectives 21(1), 1-22.

Bayne, T. (2010). The Unity of Consciousness. Oxford: Oxford University Press.

Bayne, T. and D. Chalmers (2003). What is the unity of consciousness? In A. Cleeremans (Ed.), The Unity of Consciousness, pp. 23-58. Oxford: Oxford University Press.

Bayne, T. and M. Montague (2011). Cognitive phenomenology: An introduction. In T. Bayne and M. Montague (Eds.), Cognitive Phenomenology, pp. 1-34. Oxford: Oxford University Press.

Bennett, D. J. and C. S. Hill (2014). A unity pluralist account of the unity of experience. In C. S. Hill and D. J. Bennett (Eds.), Sensory Integration and the Unity of Consciousness, pp. 233-53. Cambridge: MIT Press.

Block, N. (1995). On a confusion about a function of consciousness. Brain and Behavioral Sciences 18(2), 227-247.

Block, N. (2009). Comparing the major theories of consciousness. In M. Gazzaniga (Ed.), The Cognitive Neurosciences IV (3rd ed.)., pp. 1111-1123. Cambridge: MIT Press.

Carruthers, P. (2005). Consciousness: Essays From a Higher-Order Perspective. Oxford: Oxford University Press.

Chalmers, D. J. (1995). Facing up to the problem of consciousness. Consciousness and Emotion in Cognitive Science: Conceptual and Empirical Issues 2(3), 200-19.

Chalmers, D. J. (1996). The Conscious Mind: In Search of a Fundamental Theory. Oxford: Oxford University Press.

Churchland, P. M. (1981). Eliminative materialism and the propositional attitudes. Journal of Philosophy 78, 67-90.

Coghill, R. C., J. G. McHaffie, and Y.-F. Yen (2003). Neural correlates of interindividual differences in the subjective experience of pain. Proceedings of the National Academy of Sciences 100(14), 8538-8542.

Dehaene, S. and L. Naccache (2001). Towards a cognitive neuroscience of consciousness: basic evidence and a workspace framework. Cognition 79(1-2), 1-37.

Dennett, D. C. (1988). Quining qualia. In A. J. Marcel and E. Bisiach (Eds.), [Book Chapter]. Oxford: Oxford University Press.

Dretske, F. (1995). Naturalizing the Mind. Cambridge: MIT Press.

Edelman, G. and G. Tononi (2000). A Universe of Consciousness: How Matter Becomes Imagination. New York: Basic Books.

Farrell, B. A. (1950). Experience. Mind 59, 170-98.

Finkelstein, G. W. (2013). Emil Du Bois-Reymond : Neuroscience, Self, and Society in Nineteenth-Century Germany. Transformations: Studies in the History of Science and Technology. Cambridge: MIT Press.

Flanagan, O. J. (1992). Consciousness Reconsidered. Bradford book. Cambridge: MIT Press.

Freeman, W. J. (2000). How brains make up their minds. New York: Columbia University Press.

Gilbert, C. D. and M. Sigman (2007). Brain states: Top-down influences in sensory processing. Neuron 54(5), 677-696.

Hill, C. S. and D. J. Bennett (2014). Sensory Integration and the Unity of Consciousness. Cambridge: MIT Press.

Husserl, E. and W. Biemel (1968). Phänomenologische Psychologie, Volume 9. Dordrecht: Springer Science \& Business Media.

Husserliana, X. (1969). Zur Phänomenologie des inneren Zeitbewussteseins, ed. Rudolf Boehm. La Haya, Países Bajos: Martinus Nijhoff.

Koch, C. (2004). The Quest for Consciousness: A Neurobiological Approach. Englewood, CO: Roberts \& Company Publishers.

Koch, C. (2012). Consciousness: Confessions of a Romantic Reductionist. Cambridge: MIT Press.

Koksvik, O. (2014). Three models of phenomenal unity. Journal of Consciousness Studies 21(7-8), 105-31.

Kriegel, U. (2009). Subjective Consciousness: A Self-Representational Theory. Oxford: Oxford University Press.

Lee, G. (2014). Experiences and their parts. In C. S. Hill and D. J. Bennett (Eds.), Sensory Integration and the Unity of Consciousness, pp. 287-322. Cambridge: MIT Press.

Levine, J. (1983). Materialism and qualia: The explanatory gap. Pacific Philosophical Quarterly 64(October), 354-61.

Levine, J. (1994). Review of Owen Flanagan's Consciousness Reconsidered. The Philosophical Review 103, 353-356.

Levine, J. (2001). Purple Haze. Oxford: Oxford University Press.

McClelland, T. (2017). The problem of consciousness: Easy, hard or tricky? Topoi 36(1), 17-30.

McGinn, C. (1991). The Problem of Consciousness: Essays Toward a Resolution. Oxford: Blackwell Publishing.

Mitchell, S. D. (2003). Biological Complexity and Integrative Pluralism. Cambridge: Cambridge University Press. 
Mitchell, S. D. (2009). Unsimple Truths: Science, Complexity, and Policy. Chicago: The University of Chicago Press.

Nagel, T. (1974). What is it like to be a bat? Philosophical Review 83(October), 435-50.

Nichols, S. and S. P. Stich (2003). Mindreading. An Integrated Account of Pretence, Self-Awareness, and Understanding Other Minds. Oxford: Oxford University Press.

Nielsen, C. S., R. Staud, and D. D. Price (2009). Individual differences in pain sensitivity: Measurement, causation, and consequences. The Journal of Pain 10(3), $231-237$.

Olivares, F. A., E. Vargas, C. Fuentes, D. Martínez-Pernía, and A. Canales-Johnson (2015). Neurophenomenology revisited: secondperson methods for the study of human consciousness. Frontiers in Psychology 6(673), 1-12.

Peressini, A. (2013). Consciousness as integrated information: A provisional philosophical critique. Journal of Consciousness Studies 20(1-2), 180-206.

Peressini, A. (2014). Blurring two conceptions of subjective experience: Folk versus philosophical phenomenality. Philosophical Psychology 27(6), 862-889.

Pye, A. and P. E. Bestelmeyer (2015). Evidence for a supra-modal representation of emotion from cross-modal adaptation. Cognition 134(0), $245-251$.

Ramachandran, V. S. and E. M. Hubbard (2001). Synaesthesia: A window into perception, thought and language. Journal of Consciousness Studies 8(12), 3-34.

Rosenthal, D. M. (2005). Consciousness and Mind. Oxford: Oxford: Clarendon Press.

Seager, W. E. (1999). Theories of Consciousness: An Introduction and Assessment. New York: Routledge.

Searle, J. R. (2000). Consciousness. Annu Rev Neurosci 23, 557-578.

Silberstein, M. and A. Chemero (2012). Complexity and extended phenomenological-cognitive systems. Topics in Cognitive Science 4(1), 35-50.

Sprigge, T. L. S. and A. Montefiore (1971). Final causes. Proceedings of the Aristotelian Society, Supplementary Volumes 45, $149-192$.

Stich, S. P. (1983). From folk psychology to cognitive science: The case against belief. Cambridge: MIT Press.

Strawson, G. (2006). Realistic monism - why physicalism entails panpsychism. Journal of Consciousness Studies 13(10-11), 3-31.

Strawson, G. (2010). Radical self-awareness. In M. Siderits, E. Thompson, and D. Zahavi (Eds.), Self, No Self?: Perspectives From Analytical, Phenomenological, and Indian Traditions. Oxford: Oxford University Press.

Sytsma, J. (2014). Attributions of consciousness. Wiley Interdisciplinary Reviews: Cognitive Science 5(6), 635-648.

Sytsma, J. and E. Machery (2010). Two conceptions of subjective experience. Philosophical Studies 151(2), $299-327$.

Thompson, E., A. Lutz, and D. Cosmelli (2005). Neurophenomenology: An introduction for neurophilosophers. In Cognition and the brain: The philosophy and neuroscience movement, pp. 40-97. Cambridge: Cambridge University Press.

Tolman, E. C. (1932). Purposeful Behavior in Animals and Men. Berkeley: University of California Press.

Tononi, G. (2007). The information integration theory of consciousness. In M. Velmans and S. Schneider (Eds.), The Blackwell Companion to Consciousness, pp. 287-299. Oxford: Blackwell Publishing.

Tononi, G. (2008). Consciousness as integrated information: a provisional manifesto. The Biological Bulletin 215(3), $216-242$.

Tononi, G. and G. M. Edelman (1998). Consciousness and complexity. Science 282(5395), 1846-1851.

Tye, M. (1995). Ten Problems of Consciousness: A Representational Theory of the Phenomenal Mind. Cambridge: MIT Press.

Varela, F. (1995). Neurophenomenology: A methodological remedy for the hard problem. Journal of Consciousness Studies 3(4), $330-49$.

Vasey, M. W., M. R. Vilensky, J. H. Heath, C. N. Harbaugh, A. G. Buffington, and R. H. Fazio (2012). It was as big as my head, i swear!: biased spider size estimation in spider phobia. Journal of anxiety disorders 26(1), 20-24.

Vimal, R. (2009). Meanings attributed to the term consciousness: An overview. Journal of Consciousness Studies 16(5), 9-27.

Watzl, S. (2014). Attentional organization and the unity of consciousness. Journal of Consciousness Studies 21(7-8), 56-87.

Wertheimer, M. (1938). Laws of organization in perceptual forms. London: Harcourt, Brace \& Jovanovitch.

Wimsatt, W. C. (2007). Re-Engineering Philosophy for Limited Beings: Piecewise Approximations to Reality. Cambridge: Harvard University Press.

Witt, J. K. and M. Sugovic (2013). Spiders appear to move faster than non-threatening objects regardless of one's ability to block them. Acta Psychologica 143(3), $284-291$.

Wittgenstein, L. (1953). The Philosophical Investigations. Translated by G. E. M. Anscombe. New York: Macmillan.

Zahavi, D. (2010). Inner (Time-)Consciousness. In D. Lohmar and I. Yamaguchi (Eds.), On Time-New Contributions to the Husserlian Phenomenology of Time, pp. 319-339. Dordrecht: Springer.

Zahle, J. (2016). Methodological holism in the social sciences. In E. N. Zalta (Ed.), The Stanford Encyclopedia of Philosophy (Summer 2016 ed.). url = http://plato. stanford.edu/entries/holism-social/. 